\title{
Review:
}

\section{Multifunctional protein: cardiac ankyrin repeat protein*}

\author{
Na ZHANG, Xiao-jie XIE, Jian-an WANG ${ }^{\dagger \ddagger}$ \\ (Cardiovascular Key Lab of Zhejiang Province, Department of Cardiology, the Second Affiliated Hospital, \\ School of Medicine, Zhejiang University, Hangzhou 310009, China) \\ †E-mail: jian_an_wang@yahoo.com \\ Received Oct. 12, 2015; Revision accepted Dec. 2, 2015; Crosschecked Apr. 11, 2016
}

\begin{abstract}
Cardiac ankyrin repeat protein (CARP) not only serves as an important component of muscle sarcomere in the cytoplasm, but also acts as a transcription co-factor in the nucleus. Previous studies have demonstrated that CARP is up-regulated in some cardiovascular disorders and muscle diseases; however, its role in these diseases remains controversial now. In this review, we will discuss the continued progress in the research related to CARP, including its discovery, structure, and the role it plays in cardiac development and heart diseases.
\end{abstract}

Key words: Cardiac ankyrin repeat protein (CARP), Cardiovascular disease, Cardiac development http://dx.doi.org/10.1631/jzus.B1500247

CLC number: R34

\section{Introduction}

Cardiac ankyrin repeat protein (CARP) was first discovered in the nucleus as a transcription co-factor to regulate cardiac gene expression in 1995 (Chu et al., 1995). Subsequently, it was also found to be distributed in sarcomere I-band interacting with the giant elastic protein titin (Miller et al., 2003). Since its discovery, CARP has elicited significant interest, especially in cardiovascular and muscle diseases. The expression of CARP was increased in several diseases. Moreover, CARP mutation was found in dilated cardiomyopathy and hypertrophic cardiomyopathy, which suggests its role in diagnosis and prognosis of these diseases. However, the specific role of CARP in the progress of these diseases is still inconsistent now, which implies that the discrepancy will be crucial to deepen our understanding of CARP and open new avenues for cardiovascular diseases therapy. In this study, we primarily review the structure and role of CARP in cardiac development and heart diseases.

\footnotetext{
${ }^{\ddagger}$ Corresponding author

* Project supported by the National Natural Science Foundation of China (No. 31171392)

(Di) ORCID: Na ZHANG, http://orcid.org/0000-0002-1652-1869; Jian-an WANG, http://orcid.org/0000-0003-0409-8941

(C) Zhejiang University and Springer-Verlag Berlin Heidelberg 2016
}

\section{Discovery of CARP}

CARP was originally identified, in 1995, as a cytokine-inducible transcription factor through screening of a complementary DNA (cDNA) library prepared from interleukin- $1 \alpha$ and tumor necrosis factor- $\alpha$ stimulated human dermal microvascular endothelial cells designated as C-193 (Chu et al., 1995), and the location and sequence of C-193 and its compiled protein structure were first determined. Subsequently in 1997, rat CARP was independently isolated by three labs (Baumeister et al., 1997; Jeyaseelan et al., 1997; Zou et al., 1997), and rabbit cDNA was then cloned and its characterization was determined in 1999 (Aihara et al., 1999). In order to characterize the factors that regulate the expression of ventricular myosin light chain-2 (MLC-2v) gene, Zou et al. (1997) isolated the YB-1-associated nuclear factor from the neonatal rat cardiomyocyte cDNA library by performing a yeast-two-hybrid screening, and designated the results as CARP because of the repeated ankyrin protein domain and its exclusive expression in the heart. Jeyaseelan et al. (1997) found this protein in their search for additional cardiac-specific molecules that mediate the toxic effect of doxorubicin (DOX; adriamycin), hence they called this protein cardiac 
adriamycin-responsive protein, whose expression is down-regulated in response to adriamycin. At the same time, the muscle ankyrin repeat protein (MARP) was cloned as a gene induced in the denervated skeletal muscle of adult rats, and proved to be a rodent homologue of the human's C-193 and identical to rat's CARP (Baumeister et al., 1997). However, MARP was later identified as a family composed of three proteins: ankyrin repeat domain-containing protein 2 (ANKRD2), CARP, and the diabetes-related ankyrin repeat protein (DARP), which exert their functions together in the muscle (Miller et al., 2003). Accumulating data showed that ANKRD2 was primarily expressed in the skeletal muscle (Singal and Iliskovic, 1998; Tsukamoto et al., 2002; Miller et al., 2003), while CARP was primarily expressed in the heart (Baumeister et al., 1997; Jeyaseelan et al., 1997; Zou et al., 1997; Boengler et al., 2003; Miller et al., 2003) and DARP was expressed in both tissues (Ikeda et al., 2003; Barash et al., 2004). These represent homologous ankyrin repeat proteins, and interact together in the muscles. Recently, sheep homolog of the CARP gene was also cloned and characterized (Ma et al., 2013).

\section{CARP gene and protein structure}

CARP is encoded by the ankyrin repeat domain 1 gene (ankrd1), localized in human chromosome 10q23.31 and chromosome 19C2 in mice. Ankrd1 sequence is highly conserved among different mammalian species, with nine exons and several canonical response elements in the 5'-untranslated region, including the GATA-box, AT-rich, E-box, and TATAbox (Fig. 1). The cDNA of the human ankrd1 is 1901 base pairs long and encodes 319 amino acids (aa) with a molecular weight of $36 \mathrm{kDa}$ (Chu et al., 1995; Jeyaseelan et al., 1997; Zou et al., 1997).

The CARP protein consists of the nuclear localization signals (NLSs) (71-80 aa, 94-103 aa), PEST-like region (108-126 aa), four ankyrin-like repeats (152-283 aa), and multiple consensus protein phosphorylation sites (Chu et al., 1995; Jeyaseelan et al., 1997; Zou et al., 1997). The PEST-like region, enriched with proline $(\mathrm{P})$, glutamic acid $(\mathrm{E})$, serine $(\mathrm{S})$, and threonine $(\mathrm{T})$, is involved in rapid $\mathrm{mRNA}$ and protein degradation (Rogers et al., 1986). Therefore, it has been expressed in many short-lived proteins, such as G1 cyclins (Evans et al., 1983), c-myc, c-fos (Rogers et al., 1986), and p53 (Gronostajski et al., 1984). Ankyrin repeat protein is a 33 -aa sequence motif, mediating protein-protein interactions. It has been identified in many proteins, including cyclindependent kinase inhibitors, cytoskeletal organizers, transcriptional regulators, and developmental regulators (Sedgwick and Smerdon, 1999). CARP also contains six calsequestrin-2 (CASQ-2)-binding sites (Torrado et al., 2005) and two titin-binding sites as shown in Fig. 1.

(a) Gene

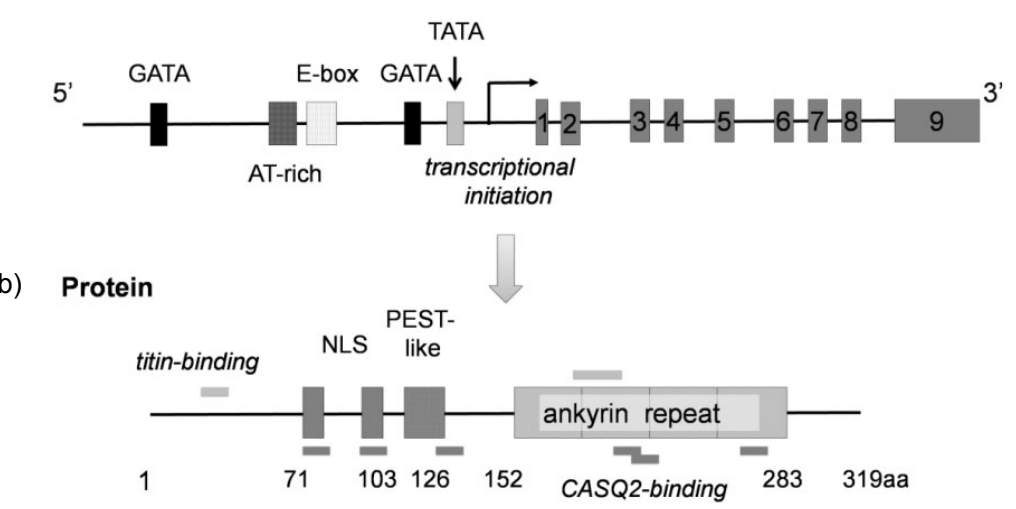

Fig. 1 Structure of the CARP gene (ankrd1) and translated protein

(a) Ankrdl sequence has 9 exons and several canonical response elements in the 5'-untranslated region, including the GATAbox, AT-rich, E-box, and TATA-box. (b) The CARP protein has 319 amino acids (aa) consisting of nuclear localization signals (NLSs) (71-80 aa, 94-103 aa), PEST-like regions (108-126 aa), and four ankyrin-like repeats (152-283 aa). CARP also contains six CASQ-2-binding sites and two titin-binding sites 


\section{Function of CARP}

CARP has been identified in both nucleus and cytoplasm, and plays different roles in different subcellular localizations and different cell types. Currently, the role of CARP is primarily characterized in cardiac and muscle tissues.

\subsection{A component of muscle sarcomere}

CARP is found in the sarcomeric I-band binding to the titin-N2A element as a member of the titin mechanosensory unit (Miller et al., 2003). The giant protein titin, also known as connectin, is anchored in the Z-disk and extends to the M-line region of the sarcomere (Fig. 2). It provides a structural framework through the association with other proteins of the sarcomere, keeps the thick filament centered in the sarcomere during activation, and functions as a molecular spring in the muscle sarcomere, which is involved in myocyte stress-sensing signaling (Labeit et al., 1997; Granzier and Labeit, 2004). CARP plays a crucial role in maintaining sarcomeric integrity, myofibrillar signaling, and stretch sensing in the heart, interacting with other sarcomeric proteins including myopalladin (Bang et al., 2001) and cardiac CASQ-2 (Miller et al., 2004; Torrado et al., 2005). Furthermore, CARP is also expressed in the nucleus function as a transcription co-factor; this dual localization may mediate the communication between the sarcomere and nucleus, transforming the muscle stretch signal to the gene transcription. However, the mechanisms of this process are not currently clear.

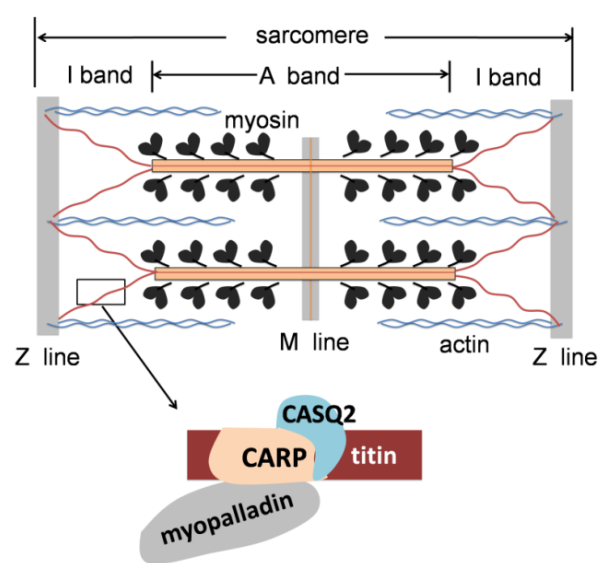

Fig. 2 CARP in sarcomere

CARP is bound to the titin-N2A elements in the sarcomeric I-band, interacting with CASQ2 and myopalladin
4.2 Nuclear transcriptional co-factor that negatively regulates cardiac gene expression and cardiac morphogenesis

CARP was initially discovered as a nuclear transcriptional co-factor, which can negatively regulate several cardiac-specific gene expressions, including MLC-2v, atrial natriuretic factor (ANF), and cardiac troponin C (cTnC) (Zou et al., 1997). All of these are cardiac early genes in heart development, and CARP was discovered very early in E7.5 (7.5 d related to the presence of a vaginal plug in females, indicating that the mating occurred), suggesting its role in cardiogenesis. However, contradictory results revealed differences in the MLC-2v and cTnC transcriptions in the muscle LIM protein deficient $\left(\mathrm{MLP}^{-/-}\right)$mice, characterized by high levels of CARP (Arber et al., 1997). Therefore, further investigations are required to clarify this issue.

\subsection{Enhancing neovascularization}

CARP mRNA and protein were found to be dramatically up-regulated in excisional wounds (Shi et al., 2005) and femoral ligation models (Boengler et al., 2003), suggesting their roles in the process of angiogenesis and arteriogenesis. Additionally, CARP was also found to be expressed in the endothelial cells and smooth muscle cells (SMCs) of the collateral artery, even the inflammatory and epithelial cells within the wound. CARP overexpression could induce neovascularization and increase blood perfusion in vivo, and promote human umbilical vein endothelial cell (HUVEC) survival and migration in vitro. These mechanisms may be due to their transcriptional regulatory abilities that activate the expression of the classic angiogenic factors (vascular endothelial growth factor, hepatic growth factor, fibroblast growth factor, etc.) or inhibit the expression of angiogenic inhibitors, or paracrine effects through activating non-vascular cell types such as fibroblasts, leukocytes, or keratinocytes (Shi et al., 2005). CARP may be a new target for stimulating neovascularization in ischemia tissue and wound healing. The mechanisms of CARP-induced neovascularization need to be further clarified.

\section{CARP and diseases}

\subsection{Cardiovascular disease}

CARP expression is increased in human heart failure and in different animal models of cardiac 
hypertrophy. The role of CARP is primarily studied in cardiovascular and muscular diseases.

\subsubsection{Cardiac hypertrophy}

Cardiac hypertrophy is an adaptive response of increased heart afterload, characterized by an increase in cardiomyocyte size and enhanced cardiac fibroblast synthesis (Frey and Olson, 2003). There is now a wealth of evidence indicating that CARP expression can be markedly induced by various hypertrophic stimuli and in distinct animal models of hypertrophy, including constriction of the abdominal aorta, spontaneously in hypertensive rats and Dahl salt-sensitive rats (Aihara et al., 2000a). Hypertrophic agonists activated p38 and Rac1 expression in mitogen-activated protein kinase (MAPK) pathways, which transcriptionally activate CARP expression through binding the muscle-CAT (M-CAT) elements in the promoter sequence. Of additional note, CARP can be rapidly induced and sustained in cardiac hypertrophy, which is different from other transiently increased hypertrophyinduced transcription factors (c-fos, c-jun, c-myc, and egr-1) (Chien et al., 1993; Sadoshima and Izumo, 1997).

However, CARP overexpression experiments were primarily performed in vitro by transfecting the CARP gene to cardiomyocyte until Song et al. (2012) first generated a cardiac-specific CARP-overexpressing transgenic (CARP Tg) mice, in which they found no differences in the heart function compared with wildtype littermate. They discovered that CARP Tg mice developed less hypertrophy than wild-type mice in cardiac hypertrophy models, including transverse aortic constriction (TAC) and isoproterenol, and concluded that CARP could attenuate cardiac hypertrophy mediated by inhibition of extracellular signal-regulated protein kinases 1 and 2 (ERK1/2) and transforming growth factor $\beta$ (TGF- $\beta$ ) pathways and then decrease fibrosis deposition in the heart. Conversely, Bang et al. (2014) found that CARP is not essential for normal cardiac development and functions in basal conditions and in response to mechanical pressure overload; Chen et al. (2014) demonstrated that CARP promoted cardiomyocyte hypertrophy through calcineurin accumulation.

By analyzing 384 hypertrophic cardiomyopathy (HCM) patients, Arimura et al. (2009) detected three ankrd1 missense mutations (Pro52Ala, Thr123Met,
Ile280Val) in HCM patients, and all mutations showed increased binding of CARP to both titin and myopalladin. These findings suggest that the binding of sarcomeric CARP to titin and myopalladin plays a pivotal role in maintaining the cardiac function. Subsequently, Crocini et al. (2013) investigated the effects of HCM-associated mutations on contraction ability after gene transfer in engineered heart tissues, providing evidence that CARP mutations influenced myocyte contractions through different mechanisms.

\subsubsection{Dilated cardiomyopathy}

Ankrdl was identified as a new gene associated with dilated cardiomyopathy (DCM) by two labs independently (Duboscq-Bidot et al., 2009; Moulik et al., 2009). Genetic and functional analyses in cardiomyocytes demonstrated that ankrdl mutations can impair CARP's nuclear function. Similarly, three missense heterozygous ankrd1 mutations (P105S, V107L, M184I) were discovered in 4 DCM patients after screening for mutations of ankrdl in 208 DCM patients (Moulik et al., 2009). While performing in vitro functional assays, Moulik et al. (2009) found that the CARP mutations altered CARP-associated protein interactions and expressions of proteins involved in key cellular pathways, such as cell cycle (p53, myogenin), apotosis (p53), growth (TGF- $\beta$, early growth response protein 1), and calcium signaling proteins (troponin T, CASQ2) when compared with wild-type CARP. These mutations resulted in disruption of the normal cardiac stretch-based signaling, providing a new pathway associated with DCM in addition to the abnormalities in structural components of the sarcomere and cytoskeleton. However, because their experiments were performed using in vitro models, these findings still need to be evaluated in animal models.

\subsubsection{Adriamycin (doxorubicin)-induced cardiomyopathy}

Adriamycin (DOX) is an effective chemotherapeutic agent used frequently to treat many human neoplasms, including breast cancer, leukemia, and sarcomas (Bristow et al., 1978). However, severe cardiotoxicity of DOX limits its clinical use (Steinherz et al., 1991; Singal and Iliskovic, 1998). The proposed mechanism for DOX-induced cardiomyopathy is the production of reactive oxygen species in cardiomyocyte mitochondria (Doroshow et al., 1980; 
Yen et al., 1996; Zhou et al., 2001). The characteristic features of DOX-induced cardiomyopathy are the loss of myofibrils and the vacuolization of cardiac myocytes (Singal and Iliskovic, 1998).

Previous studies demonstrated that DOX also depleted GATA4 expression in cardiomyocytes, and preservation of GATA4 levels prevented DOXinduced cardiomyocyte death (Kim et al., 2003; Aries et al., 2004). CARP was once called the cardiac adriamycin-responsive protein, because of the fact that its expression is down-regulated in response to adriamycin (Jeyaseelan et al., 1997), which was confirmed in subsequent studies (Aihara et al., $2000 \mathrm{~b}$ ). Of note, CARP was reported as a downstream target of GATA4 (Kuo et al., 1999; Kim et al., 2003; Chen et al., 2012). Therefore, GATA4 and CARP would be therapeutic targets in DOX-induced cardiomyopathy.

\subsubsection{Cardiac ischemia injury and myocardial apoptosis}

Hypoxia and ischemia/reperfusion (I/R) injuries in neonatal rat cardiomyocytes and $\mathrm{I} / \mathrm{R}$ rat hearts can induce apoptosis-related gene GADD153 overexpression, resulting in the down-regulation of CARP (Han et al., 2005; Lee et al., 2009). These studies demonstrated that hypoxia could down-regulate CARP expression in cardiomyocytes through GADD153. Conversely, CARP was found to be significantly increased in the swine model of transient ischemia (Depre et al., 2001). These studies consistently suggested the protective role of CARP in cardiac ischemia injuries. However, a recent study revealed that overexpression of CARP enhanced cardiomyocyte apoptosis by promoting p53 activation and mitochondrial dysfunction in rodents (Shen et al., 2015). The exact role of CARP on myocardial apoptosis needs further studies to clarify the initial results.

\subsubsection{Heart failure}

CARP mRNA and protein levels were markedly increased in the canine model of pacing-induced heart failure and human heart failure due to dilated or ischemic cardiomyopathy; however, it should be noted that this study only examined left ventricle-derived specimens (Zolk et al., 2002). Subsequently, overcoming this limitation, it was shown that CARP down-regulated in atria and up-regulated in ventricles were evident in diastolic heart failure, while systolic heart failure results in up-regulation in both atria and ventricles occurring in the pig heart failure model. Interestingly, CARP presented a left-right asymmetric distribution with protein levels higher in the left as compared to the right ventricle (Torrado et al., 2004; 2006). It still obscures the role and mechanisms of CARP asymmetric distribution in heart failure.

\subsubsection{Atherosclerosis}

It was recently reported that CARP was involved in inhibition of atherosclerotic lesion formation (de Waard et al., 2003). CARP expression was observed in endothelial cells and quiescent intimal SMCs in human plaque. CARP-expressing SMCs are different from medical activated SMCs. However, CARP is not identified in quiescent SMCs in healthy vessels. Furthermore, TGF- $\beta$ could activate CARP expression to inhibit the proliferation of vascular smooth muscle cells (VSMCs) (Kanai et al., 2001). Collectively, these data suggest that CARP might be involved in the transition of activated SMCs into quiescent SMCs, thereby inhibiting the plaque progress.

\subsection{Muscle disease}

In the skeletal muscle, CARP expression is found to be low under basal conditions but could be induced in several circumstances such as exercise, muscular atrophy, amyotrophic lateral sclerosis (ALS), and other muscle pathologies (Carson et al., 2002; Tsukamoto et al., 2002; Nakada et al., 2003a; 2003b; Barash et al., 2004; Witt et al., 2004; Hentzen et al., 2006). In transient or definitive denervation-induced muscle atrophy and different muscular dystrophy models, the expression of CARP was persistently up-regulated, suggesting that it is a hub protein involved in the muscular pathological pathway. To further understand its contribution to muscle diseases, adenovirus fused with CARP coding sequence was injected into the tibial anterior muscle of normal mice. The results demonstrated no difference in muscle weight or histological appearance compared with the untreated mice, but slow-twitch fiber was reduced, suggesting that CARP overexpression in wild-type mice does not induce atrophy, but alters the fiber type composition (Laure et al., 2009). In clinical studies, it has been reported that in congenital myopathies, CARP was expressed in severely damaged myofibers, but not detected in the central core disease (Nakada 
et al., 2003a). These findings suggest that immunohistochemical evaluation of CARP may be helpful in the diagnosis of some congenital myopathies. Furthermore, CARP was found to be a sensitive and specific marker for rhabdomyosarcoma and it would be attributed in the diagnosis of rhabdomyosarcoma (Ishiguro et al., 2008). However, the mechanism of CARP up-regulation and its exact role in muscular diseases remain obscure, possibly becoming a target for muscular disease therapy.

\subsection{Other diseases}

CARP mutation was identified in the total anomalous pulmonary venous return disease, a congenital heart defect in which pulmonary veins fail to enter the left atrium and drain instead into the right atrium or one of its venous tributaries. The mutation affected PEST-motif in CARP protein, thus enhancing the stability of the CARP protein (Cinquetti et al., 2008). Increased CARP expression was also found in renal podocytes positively correlated with the severity of proteinuria in patients with lupus nephritis (Matsuura et al., 2007) and cisplatin resistance in ovarian cancer chemotherapy (Scurr et al., 2008), and CARP represents a novel target to sensitize tumors to platinum-based drugs (Lei et al., 2015). Gene expression profiling following a crushing injury of the peripheral and central dorsal root ganglion neurons suggests that CARP expression is necessary for nerve regeneration (Stam et al., 2007).

\section{Conclusions}

CARP is a multifunctional protein, which acts as a nucleus transcriptional co-factor negatively regulating cardiac genes and plays a significant role in different heart diseases, and is a component of sarcomere. Due to the important and multifunctional role of CARP, it could become a new diagnostic marker and therapeutic target of cardiovascular and muscle diseases after determining its role and understanding the mechanisms underlying the various roles it can assume.

\section{Compliance with ethics guidelines}

Na ZHANG, Xiao-jie XIE, and Jian-an WANG declare that they have no conflict of interest.

This article does not contain any studies with human or animal subjects performed by any of the authors.

\section{References}

Aihara, Y., Kurabayashi, M., Arai, M., et al., 1999. Molecular cloning of rabbit CARP cDNA and its regulated expression in adriamycin-cardiomyopathy. Biochim. Biophys. Acta, 1447(2-3):318-324. http://dx.doi.org/10.1016/S0167-4781(99)00171-2

Aihara, Y., Kurabayashi, M., Saito, Y., et al., 2000a. Cardiac ankyrin repeat protein is a novel marker of cardiac hypertrophy: role of M-CAT element within the promoter. Hypertension, 36(1):48-53. http://dx.doi.org/10.1161/01.HYP.36.1.48

Aihara, Y., Kurabayashi, M., Tanaka, T., et al., $2000 \mathrm{~b}$. Doxorubicin represses CARP gene transcription through the generation of oxidative stress in neonatal rat cardiac myocytes: possible role of serine/threonine kinase-dependent pathways. J. Mol. Cell. Cardiol., 32(8):1401-1414. http://dx.doi.org/10.1006/jmcc.2000.1173

Arber, S., Hunter, J.J., Ross, J.Jr., et al., 1997. MLP-deficient mice exhibit a disruption of cardiac cytoarchitectural organization, dilated cardiomyopathy, and heart failure. Cell, 88(3):393-403.

http://dx.doi.org/10.1016/S0092-8674(00)81878-4

Aries, A., Paradis, P., Lefebvre, C., et al., 2004. Essential role of GATA-4 in cell survival and drug-induced cardiotoxicity. PNAS, 101(18):6975-6980. http://dx.doi.org/10.1073/pnas.0401833101

Arimura, T., Bos, J.M., Sato, A., et al., 2009. Cardiac ankyrin repeat protein gene $(A N K R D 1)$ mutations in hypertrophic cardiomyopathy. J. Am. Coll. Cardiol., 54(4):334-342. http://dx.doi.org/10.1016/j.jacc.2008.12.082

Bang, M.L., Mudry, R.E., McElhinny, A.S., et al., 2001. Myopalladin, a novel 145-kilodalton sarcomeric protein with multiple roles in Z-disc and I-band protein assemblies. J. Cell Biol., 153(2):413-428. http://dx.doi.org/10.1083/jcb.153.2.413

Bang, M.L., Gu, Y., Dalton, N.D., et al., 2014. The muscle ankyrin repeat proteins CARP, Ankrd2, and DARP are not essential for normal cardiac development and function at basal conditions and in response to pressure overload. PLoS ONE, 9(4):e93638. http://dx.doi.org/10.1371/journal.pone.0093638

Barash, I.A., Mathew, L., Ryan, A.F., et al., 2004. Rapid muscle-specific gene expression changes after a single bout of eccentric contractions in the mouse. Am. J. Physiol. Cell. Physiol., 286(2):C355-C364. http://dx.doi.org/10.1152/ajpcell.00211.2003

Baumeister, A., Arber, S., Caroni, P., 1997. Accumulation of muscle ankyrin repeat protein transcript reveals local activation of primary myotube endcompartments during muscle morphogenesis. J. Cell Biol., 139(5):1231-1242. http://dx.doi.org/10.1083/jcb.139.5.1231

Boengler, K., Pipp, F., Fernandez, B., et al., 2003. Arteriogenesis is associated with an induction of the cardiac ankyrin repeat protein (carp). Cardiovasc. Res., 59(3):573-581. http://dx.doi.org/10.1016/S0008-6363(03)00511-X

Bristow, M.R., Billingham, M.E., Mason, J.W., et al., 1978. 
Clinical spectrum of anthracycline antibiotic cardiotoxicity. Cancer Treat. Rep., 62(6):873-879.

Carson, J.A., Nettleton, D., Reecy, J.M., 2002. Differential gene expression in the rat soleus muscle during early work overload-induced hypertrophy. FASEB J., 16(2): 207-209. http://dx.doi.org/10.1096/fj.01-0544fje

Chen, B., Zhong, L., Roush, S.F., et al., 2012. Disruption of a GATA4/Ankrd1 signaling axis in cardiomyocytes leads to sarcomere disarray: implications for anthracycline cardiomyopathy. PLOS ONE, 7(4):e35743. http://dx.doi.org/10.1371/journal.pone.0035743

Chen, C., Shen, L., Cao, S., et al., 2014. Cytosolic CARP promotes angiotensin II- or pressure overload-induced cardiomyocyte hypertrophy through calcineurin accumulation. PLOS ONE, 9(8):e104040.

http://dx.doi.org/10.1371/journal.pone.0104040

Chien, K.R., Zhu, H., Knowlton, K.U., et al., 1993. Transcriptional regulation during cardiac growth and development. Annu. Rev. Physiol., 55:77-95.

http://dx.doi.org/10.1146/annurev.ph.55.030193.000453

Chu, W., Burns, D.K., Swerlick, R.A., et al., 1995. Identification and characterization of a novel cytokine-inducible nuclear protein from human endothelial cells. J. Biol. Chem., 270(17):10236-10245. http://dx.doi.org/10.1074/jbc.270.17.10236

Cinquetti, R., Badi, I., Campione, M., et al., 2008. Transcriptional deregulation and a missense mutation define ANKRD1 as a candidate gene for total anomalous pulmonary venous return. Hum. Mutat., 29(4):468-474. http://dx.doi.org/10.1002/humu.20711

Crocini, C., Arimura, T., Reischmann, S., et al., 2013. Impact of ANKRD1 mutations associated with hypertrophic cardiomyopathy on contraction parameters of engineered heart tissue. Basic Res. Cardiol., 108(3):349. http://dx.doi.org/10.1007/s00395-013-0349-x

Depre, C., Tomlinson, J.E., Kudej, R.K., et al., 2001. Gene program for cardiac cell survival induced by transient ischemia in conscious pigs. PNAS, 98(16):9336-9341. http://dx.doi.org/10.1073/pnas.171297498

de Waard, V., van Achterberg, T.A., Beauchamp, N.J., et al., 2003. Cardiac ankyrin repeat protein (CARP) expression in human and murine atherosclerotic lesions: activin induces CARP in smooth muscle cells. Arterioscler. Thromb. Vasc. Biol., 23(1):64-68. http://dx.doi.org/10.1161/01.ATV.0000042218.13101.50

Doroshow, J.H., Locker, G.Y., Myers, C.E., 1980. Enzymatic defenses of the mouse heart against reactive oxygen metabolites: alterations produced by doxorubicin. J. Clin. Invest., 65(1):128-135. http://dx.doi.org/10.1172/JCI109642

Duboscq-Bidot, L., Charron, P., Ruppert, V., et al., 2009. Mutations in the ANKRD1 gene encoding CARP are responsible for human dilated cardiomyopathy. Eur. Heart J., 30(17):2128-2136. http://dx.doi.org/10.1093/eurheartj/ehp225
Evans, T., Rosenthal, E.T., Youngblom, J., et al., 1983. Cyclin: a protein specified by maternal mRNA in sea urchin eggs that is destroyed at each cleavage division. Cell, $\mathbf{3 3}(2)$ : 389-396. http://dx.doi.org/10.1016/0092-8674(83)90420-8

Frey, N., Olson, E.N., 2003. Cardiac hypertrophy: the good, the bad, and the ugly. Ann. Rev. Physiol., 65:45-79. http:// dx.doi.org/10.1146/annurev.physiol.65.092101.142243

Granzier, H.L., Labeit, S., 2004. The giant protein titin: a major player in myocardial mechanics, signaling, and disease. Circ. Res., 94(3):284-295. http://dx.doi.org/10.1161/01.RES.0000117769.88862.F8

Gronostajski, R.M., Goldberg, A.L., Pardee, A.B., 1984. Energy requirement for degradation of tumor-associated protein p53. Mol. Cell. Biol., 4(3):442-448.

Han, X.J., Chae, J.K., Lee, M.J., et al., 2005. Involvement of GADD153 and cardiac ankyrin repeat protein in hypoxia-induced apoptosis of $\mathrm{H} 9 \mathrm{c} 2$ cells. J. Biol. Chem., 280(24):23122-23129. http://dx.doi.org/10.1074/jbc.M501095200

Hentzen, E.R., Lahey, M., Peters, D., et al., 2006. Stressdependent and -independent expression of the myogenic regulatory factors and the $M A R P$ genes after eccentric contractions in rats. J. Physiol., 570(Pt 1):157-167. http://dx.doi.org/10.1113/jphysiol.2005.093005

Ikeda, K., Emoto, N., Matsuo, M., et al., 2003. Molecular identification and characterization of a novel nuclear protein whose expression is up-regulated in insulinresistant animals. J. Biol. Chem., 278(6):3514-3520. http://dx.doi.org/10.1074/jbc.M204563200

Ishiguro, N., Motoi, T., Araki, N., et al., 2008. Expression of cardiac ankyrin repeat protein, CARP, in malignant tumors: diagnostic use of CARP protein immunostaining in rhabdomyosarcoma. Hum. Pathol., 39(11):1673-1679. http://dx.doi.org/10.1016/j.humpath.2008.04.009

Jeyaseelan, R., Poizat, C., Baker, R.K., et al., 1997. A novel cardiac-restricted target for doxorubicin. CARP, a nuclear modulator of gene expression in cardiac progenitor cells and cardiomyocytes. J. Biol. Chem., 272(36):22800-22808. http://dx.doi.org/10.1074/jbc.272.36.22800

Kanai, H., Tanaka, T., Aihara, Y., et al., 2001. Transforming growth factor- $\beta /$ Smads signaling induces transcription of the cell type-restricted ankyrin repeat protein CARP gene through CAGA motif in vascular smooth muscle cells. Circ. Res., 88(1):30-36. http://dx.doi.org/10.1161/01.RES.88.1.30

Kim, Y., Ma, A.G., Kitta, K., et al., 2003. Anthracyclineinduced suppression of GATA-4 transcription factor: implication in the regulation of cardiac myocyte apoptosis. Mol. Pharmacol., 63(2):368-377. http://dx.doi.org/10.1124/mol.63.2.368

Kuo, H., Chen, J., Ruiz-Lozano, P., et al., 1999. Control of segmental expression of the cardiac-restricted ankyrin repeat protein gene by distinct regulatory pathways in murine cardiogenesis. Development, 126(19):4223-4234.

Labeit, S., Kolmerer, B., Linke, W.A., 1997. The giant protein 
titin. Emerging roles in physiology and pathophysiology. Circ. Res., 80(2):290-294.

http://dx.doi.org/10.1161/01.RES.80.2.290

Laure, L., Suel, L., Roudaut, C., et al., 2009. Cardiac ankyrin repeat protein is a marker of skeletal muscle pathological remodelling. FEBS J., 276(3):669-684. http://dx.doi.org/10.1111/j.1742-4658.2008.06814.x

Lee, M.J., Kwak, Y.K., You, K.R., et al., 2009. Involvement of GADD153 and cardiac ankyrin repeat protein in cardiac ischemia-reperfusion injury. Exp. Mol. Med., 41(4):243-252. http://dx.doi.org/10.3858/emm.2009.41.4.027

Lei, Y., Henderson, B.R., Emmanuel, C., et al., 2015. Inhibition of ANKRD1 sensitizes human ovarian cancer cells to endoplasmic reticulum stress-induced apoptosis. Oncogene, 34(4):485-495.

http://dx.doi.org/10.1038/onc.2013.566

Ma, G., Wang, H., Li, Y., et al., 2013. Cloning, expression, and bioinformatics analysis of the sheep CARP gene. Mol. Cell. Biochem., 378(1-2):29-37. http://dx.doi.org/10.1007/s11010-013-1590-1

Matsuura, K., Uesugi, N., Hijiya, N., et al., 2007. Upregulated expression of cardiac ankyrin-repeated protein in renal podocytes is associated with proteinuria severity in lupus nephritis. Hum. Pathol., 38(3):410-419.

http://dx.doi.org/10.1016/j.humpath.2006.09.006

Miller, M.K., Bang, M.L., Witt, C.C., et al., 2003. The muscle ankyrin repeat proteins: CARP, ankrd2/Arpp and DARP as a family of titin filament-based stress response molecules. J. Mol. Biol., 333(5):951-964. http://dx.doi.org/10.1016/j.jmb.2003.09.012

Miller, M.K., Granzier, H., Ehler, E., et al., 2004. The sensitive giant: the role of titin-based stretch sensing complexes in the heart. Trends Cell Biol., 14(3):119-126. http://dx.doi.org/10.1016/j.tcb.2004.01.003

Moulik, M., Vatta, M., Witt, S.H., et al., 2009. ANKRD1, the gene encoding cardiac ankyrin repeat protein, is a novel dilated cardiomyopathy gene. J. Am. Coll. Cardiol., 54(4): 325-333. http://dx.doi.org/10.1016/j.jacc.2009.02.076

Nakada, C., Oka, A., Nonaka, I., et al., 2003a. Cardiac ankyrin repeat protein is preferentially induced in atrophic myofibers of congenital myopathy and spinal muscular atrophy. Pathol. Int., 53(10):653-658. http://dx.doi.org/10.1046/j.1440-1827.2003.01541.x

Nakada, C., Tsukamoto, Y., Oka, A., et al., 2003b. Cardiacrestricted ankyrin-repeated protein is differentially induced in duchenne and congenital muscular dystrophy. Lab. Invest., 83(5):711-719.

Rogers, S., Wells, R., Rechsteiner, M., 1986. Amino acid sequences common to rapidly degraded proteins: the PEST hypothesis. Science, 234(4774):364-368. http://dx.doi.org/10.1126/science.2876518

Sadoshima, J., Izumo, S., 1997. The cellular and molecular response of cardiac myocytes to mechanical stress. Ann. Rev. Physiol., 59:551-571.

http://dx.doi.org/10.1146/annurev.physiol.59.1.551
Scurr, L.L., Guminski, A.D., Chiew, Y.E., et al., 2008. Ankyrin repeat domain 1, ANKRD1, a novel determinant of cisplatin sensitivity expressed in ovarian cancer. Clin. Cancer Res., 14(21):6924-6932. http://dx.doi.org/10.1158/1078-0432.CCR-07-5189

Sedgwick, S.G., Smerdon, S.J., 1999. The ankyrin repeat: a diversity of interactions on a common structural framework. Trends Biochem. Sci., 24(8):311-316. http://dx.doi.org/10.1016/S0968-0004(99)01426-7

Shen, L., Chen, C., Wei, X., et al., 2015. Overexpression of ankyrin repeat domain 1 enhances cardiomyocyte apoptosis by promoting $\mathrm{p} 53$ activation and mitochondrial dysfunction in rodents. Clin. Sci., 128(10):665-678. http://dx.doi.org/10.1042/CS20140586

Shi, Y., Reitmaier, B., Regenbogen, J., et al., 2005. CARP, a cardiac ankyrin repeat protein, is up-regulated during wound healing and induces angiogenesis in experimental granulation tissue. Am. J. Pathol., 166(1):303-312. http://dx.doi.org/10.1016/S0002-9440(10)62254-7

Singal, P.K., Iliskovic, N., 1998. Doxorubicin-induced cardiomyopathy. New Engl. J. Med., 339(13):900-905. http://dx.doi.org/10.1056/NEJM199809243391307

Song, Y., Xu, J., Li, Y., et al., 2012. Cardiac ankyrin repeat protein attenuates cardiac hypertrophy by inhibition of ERK1/2 and TGF- $\beta$ signaling pathways. PLOS ONE, 7(12):e50436. http://dx.doi.org/10.1371/journal.pone.0050436

Stam, F.J., MacGillavry, H.D., Armstrong, N.J., et al., 2007. Identification of candidate transcriptional modulators involved in successful regeneration after nerve injury. Eur. J. Neurosci., 25(12):3629-3637. http://dx.doi.org/10.1111/j.1460-9568.2007.05597.x

Steinherz, L.J., Steinherz, P.G., Tan, C.T., et al., 1991. Cardiac toxicity 4 to 20 years after completing anthracycline therapy. JAMA, 266(12):1672-1677. http://dx.doi.org/10.1001/jama.1991.03470120074036

Torrado, M., López, E., Centeno, A., et al., 2004. Left-right asymmetric ventricular expression of CARP in the piglet heart: regional response to experimental heart failure. Eur. J. Heart Fail., 6(2):161-172. http://dx.doi.org/10.1016/j.ejheart.2003.11.004

Torrado, M., Nespereira, B., López, E., et al., 2005. ANKRD1 specifically binds CASQ2 in heart extracts and both proteins are co-enriched in piglet cardiac Purkinje cells. $J$. Mol. Cell. Cardiol., 38(2):353-365.

http://dx.doi.org/10.1016/j.yjmcc.2004.11.034

Torrado, M., Nespereira, B., Bouzamayor, Y., et al., 2006. Differential atrial versus ventricular ANKRD1 gene expression is oppositely regulated at diastolic heart failure. FEBS Lett., 580(17):4182-4187. http://dx.doi.org/10.1016/j.febslet.2006.06.073

Tsukamoto, Y., Senda, T., Nakano, T., et al., 2002. Arpp, a new homolog of carp, is preferentially expressed in type 1 skeletal muscle fibers and is markedly induced by denervation. Lab. Invest., 82(5):645-655.

Witt, C.C., Ono, Y., Puschmann, E., et al., 2004. Induction and 
myofibrillar targeting of CARP, and suppression of the Nkx2.5 pathway in the MDM mouse with impaired titin-based signaling. J. Mol. Biol., 336(1):145-154. http://dx.doi.org/10.1016/j.jmb.2003.12.021

Yen, H.C., Oberley, T.D., Vichitbandha, S., et al., 1996. The protective role of manganese superoxide dismutase against adriamycin-induced acute cardiac toxicity in transgenic mice. J. Clin. Invest., 98(5):1253-1260. http://dx.doi.org/10.1172/JCI118909

Zhou, S., Palmeira, C.M., Wallace, K.B., 2001. Doxorubicininduced persistent oxidative stress to cardiac myocytes. Toxicol. Lett., 121(3):151-157. http://dx.doi.org/10.1016/S0378-4274(01)00329-0

Zolk, O., Frohme, M., Maurer, A., et al., 2002. Cardiac ankyrin repeat protein, a negative regulator of cardiac gene expression, is augmented in human heart failure. Biochem. Biophys. Res. Commun., 293(5):1377-1382. http://dx.doi.org/10.1016/S0006-291X(02)00387-X
Zou, Y., Evans, S., Chen, J., et al., 1997. CARP, a cardiac ankyrin repeat protein, is downstream in the $\mathrm{Nkx} 2-5$ homeobox gene pathway. Development, 124(4):793-804.

\section{中文概要}

题 目: 心针重复蛋白的研究进展

概 要: 心针重复蛋白 (CARP) 是一个双重定位的蛋白, 既可以在胞浆中作为肌节的结构组成蛋白, 又定 位于细胞核中作为转录共刺激因子调节其他基 因的表达。研究发现CARP在多种心血管疾病及 肌肉疾病中表达升高, 但其在疾病中的作用尚存 在争议。本文就CARP的研究进展进行综述, 概 述CARP的发现过程和结构, 并对CARP在疾病中 的作用的争议进行总结分析。

关键词: 心针重复蛋白; 心血管疾病; 心脏发育 